\title{
ANALISIS PENGARUH ORIENTASI KEWIRAUSAHAAN DAN PASAR SERTA INOVASI TERHADAP KINERJA EKONOMI PRODUKTIF KELOMPOK USAHA BERSAMA (UEP KUBE) DI KOTA BUKITTINGGI SUMATRERA BARAT
}

\section{ANALYSIS OF THE EFFECT OF CORPORATE AND MARKET ORIENTATION AND INNOVATION ON THE PRODUCTIVE ECONOMIC PERFORMANCE OF THE JOINT BUSINESS BUSINESS GROUP (UEP KUBE) IN THE BUKITTINGGI CITY OF WEST SUMATRERA}

\author{
Irwan Ch 1a, T T Andari 1, M N Mukmin ${ }^{1}$ \\ 1Fakultas Ekonomi Universitas Djuanda Bogor Universitas Djuanda Jl. Tol Ciawi . \\ a Korespondensi: Irwan Ch, E-mail: irwan.ch@unida.ac.id \\ (Diterima: 07-11-2019; Ditelaah: 10-11-2019; Disetujui: 02-01-2020)
}

\begin{abstract}
Micro, Small and Medium Enterprises greatly contribute to the Indonesian economy, both in terms of the number of business units, employment and contribution to Gross Domestic Product (GDP), one of which is the Productive Business Group (UEP KUBe) Productive Economic Business. The purpose of this study is to analyze and understand the effect of entrepreneurial marketing (Entrepreneurship Orientation and Market Orientation and Innovation) on Financial Performance using SEM (Structural Equation Model) data analysis techniques. The results showed that entrepreneurial marketing, consisting of Entrepreneurship Orientation, Market Orientation, and Innovation had a significant effect on the Financial Performance of Productive Economic Business Joint Business Groups (UEP KUBe). For Entrepreneurship Orientation and Market Orientation, the positive effect is in improving Financial Performance. Innovation has a negative influence on Financial Performance, this is due to the Productive Economic Business Joint Business Group (UEP KUBe) is a Micro, Small Business, while innovation requires costs, which of course will negatively affect Financial Performance (especially in the short term).
\end{abstract}

Keywords: Innovation, Performance of Micro, Small and Medium Enterprises, entrepreneurial orientation, market orientation.

\begin{abstract}
ABSTRAK
Usaha Mikro Kecil dan Menengah memberikan kontribusi yang besar terhadap perekonomian Indonesia, baik dari sisi jumlah unit usaha, penyerapan tenaga kerja dan kontribusi terhadap Produk Domestik Bruto (PDB), salah satu bentuknya adalah Usaha Ekonomi Produktif Kelompok Usaha Bersama (UEP KUBe). Adapun tujuan penelitian ini untuk menganalisis dan memahami pengaruh pemasaran kewirausahaan (Orientasi Kewirausahaan dan Orientasi Pasar Serta Inovasi) terhadap Kinerja Keuangan dengan menggunakan teknik analisis data SEM (Stuctural Equition Model). Hasil penelitian menunjukkan bahwa pemasaran kewirausahaan yang terdiri dari Orientasi Kewirausahaan, Orientasi Pasar dan Inovasi berpengaruh signifikan kepada Kinerja Keuangan Usaha Ekonomi Produktif Kelompok Usaha Bersama (UEP KUBe). Untuk Orientasi Kewirausahaan dan Orientasi Pasar pengaruhnya positif dalam meningkatkan Kinerja Keuangan. Adapun
\end{abstract}


Inovasi mempunyai pengaruh negatif terhadap Kinerja Keuangan, hal ini disebabkan Usaha Ekonomi Produktif Kelompok Usaha Bersama (UEP KUBe) ini merupakan Usaha Mikro Kecil, sedangkan inovasi membutuhkan biaya, yang tentunya akan berpengaruh negatif terhadap Kinerja Keuangan (terutama untuk jangka pendek).

Kata kunci: Inovasi, Kinerja Usaha Mikro Kecil Menengah, orientasi kewirausahaan, orientasi pasar.

Irwan, Ch., Andari, T. T., \& Mukmin, M. M. (2020). Analisis Pengaruh Orientasi

Kewirausahaan dan Pasar serta Inovasi Terhadap Kinerja Ekonomi Produktif Kelompok

Usaha Bersama (UEP KUBE) di Kota Bukit Tinggi Sumatera Barat. Jurnal Sosial Humaniora, 11(1), 40-52.

\section{PENDAHULUAN}

Usaha Mikro Kecil dan Menengah adalah salah satu pendorong pertumbuhan ekonomi di Indonesia, dengan sumbangan Rp7.740 triliun lebih terhadap Produk Domestik Bruto (PDB) tahun 2017 dan penyerapan tenaga kerja lebih dari 116 juta orang serta 66.922.617 unit usaha atau 99,99\% dari jumlah pengelola/pelaku usaha di Indonesia (BPS, 2018). Salah satu bentuk Usaha Mikro, Kecil dan Menengah tersebut adalah Usaha Ekonomi Produktif Kelompok Usaha Bersama (UEP KUBe) yang keberadaannya semakin tumbuh dan berkembang.

Pada prinsipnya Usaha Mikro, Kecil dan Menengah terus dikembangkan/ dioptimalkan, mengingat perannya dalam perekonomian dan penyerapan tenaga kerja, terutama setelah krisis (keuangan dan ekonomi) melanda Indonesia tahun 1997/1998. Peran Usaha Mikro, Kecil dan Menengah sebagaimana diuraikan diatas, baik terhadap Produk Domestik Bruto maupun penyerapan tenaga kerja, maka aktivitasnya perlu lebih didorong lagi dan dikembangkan lebih lanjut untuk meningkatkan kinerja usahanya.

Dalam upaya meningkatkan kinerja usaha tersebut, perlu diperhatikan beberapa hal yaitu (1) Orientasi Kewirausahaan, (2) Orientasi Pasar, dan (3) Inovasi. Untuk itu pelaku usaha Usaha Ekonomi Produktif Kelompok Usaha Bersama (UEP KUBe) perlu lebih didorong untuk memahami lebih baik akan pentingnya ketiga hal tersebut dalam meningkatkan kinerja, ke posisi yang lebih unggul dan kompetitif (Idar dan Mahmood, 2011).

Orientasi Kewirausahaan merupakan kemampuan yang dipunyai pelaku usaha dan menjadi dasar dalam menemukan peluang usaha menuju kesuksesan. Oleh sebab itu, dipandang mempunyai peranan utama dalam peningkatan kinerja usaha dan kompetitif usaha ditengah-tengah persaingan usaha yang ketat (Zahra dan Covin, 1995).

Para ahli telah menyatakan bahwa perusahaan-perusahaan yang berorientasi pasar akan mempunyai kinerja unggul dari perusahaan-perusahaan lainnya. Orientasi Pasar adalah salah satu faktor yang tidak berwujud, tetapi mempunyai dampak atas kinerja perusahaan (Krohmer, Workman dan Homburg, 2005). Di samping itu, Orientasi Pasar yaitu suatu budaya bisnis yang akan menciptakan kinerja unggul dengan menciptakan nilai bagi pelanggan (Slater dan Narver, 2000).

Pengaruh antara Orientasi Kewirausahaan dan Orientasi Pasar terhadap kinerja perusahaan Usaha Kecil Menengah sektor manufaktur garmen, telah pernah dilakukan di Srilanka oleh Kumara et al (2014). Penelitian dimaksudkan untuk menganalisis tentang faktor-utama peningkatan kinerja Usaha Kecil Menengah yang terlibat dalam manufaktur garmen. Hasil penelitian menunjukkan bahwa terdapat pengaruh Orientasi Pasar dan Orientasi Kewirausahaan dengan kinerja usaha secara positif (Silviasih, Slamet dan Iskandar, 2016). 
Orientasi Kewirausahaan yaitu kemampuan pelaku usaha untuk melihat peluang usaha baru, dengan indikator: (1) standarisasi, (2) formalisasi, (3) spesialisasi, (4) sistem perencanaan dan pengendalian, dan (5) sistem informasi eksternal (Messeghen, 2003). Adapun (Ginsberg, 2011) menjelaskan bahwa Orientasi Kewirausahaan sebagai kecenderungan individu (pelaku usaha) untuk melakukan inovasi, proaktif, dan mau mengambil risiko dalam memulai usaha. Di lain pihak, Orientasi Kewirausahaan dipahami sebagai kecenderungan manajemen puncak untuk mengambil risiko yang telah diperhitungkan, inovatif dan proaktif (Morris dan Paul, 2007). Dengan demikian, maka Orientasi Kewirausahaan merupakan sikap pelaku usaha yang proaktif dan inovatif serta berani mengambil resiko dalam mengelola usahanya (risk taker).

Kasali dalam Silviasih, (Slamet dan Iskandar 2010) menjelaskan bahwa Inovasi adalah kemampuan untuk melihat permasalahan yang ada dengan cara-cara baru dan dapat juga diluar kebiasaan (out of the box thinking). Tindakan proaktif yaitu mencari kesempatan baru yang mungkin berhubungan ataupun tidak berhubungan dengan lini operasi saat ini. Keberanian mengambil risiko yaitu tingkat kesediaan pelaku usaha untuk berkomitmen terhadap sumber daya yang berisiko dengan jumlah yang besar.

Pengaruh Orientasi Pasar terhadap Kinerja Silviasih, Slamet dan Iskandar (2010) telah berhasil menghimpun berberapa hasil penelitian yang menunjukkan bahwa Orientasi Pasar berpengaruh terhadap Kinerja Usaha, yaitu:

Orientasi Pasar berdampak langsung terhadap kinerja Usaha Kecil Menengah (Kelson, 2012; Wilson et al, 2014). Orientasi Pasar membantu perusahaan menetapkan strategi dan pendekatan untuk memahami pasar (Morgan, Vorhies dan Autry, 2009). Orientasi Pasar memberikan pemahaman yang baik tentang bisnis dan lingkungannya, sehingga kebutuhan pelanggan akan terpenuhi dengan cara yang lebih baik (Pandanyi dan Grainer, 2005). Kinerja yang lebih baik dalam memahami pelanggan dan pesaingnya, akan dimiliki oleh perusahaan yang berorientasi pasar (Greenley dan Lings, 2009). Orientasi pasar yang diterapkan agar dapat meningkatkan hubungan dengan pelanggan, sehingga menumbuhkan kinerja penjualan, pertumbuhan, pangsa pasar dan profit (Morgan dan Hunt, 1994 dalam Shehu dan Mahmood, 2014). Orientasi Pasar menunjukkan bahwa terdapat korelasi positif dan sangat signifikan antara Orientasi Pasar dan Kinerja perusahaan (Richard, Beverly dan Michael, 2012).

Orientasi Pasar memiliki efek langsung terhadap kinerja perusahaan bukan hanya pada hasil pemasaran, tetapi orientasi pasar telah menjadi unsur penting yang telah menjembatani penelitian antara pemasaran dan manajemen (Ketchen dan Hult, 2001).

Orientasi Pasar dapat meningkatkan kinerja perusahaan di pasar. Adapun ciri perusahaan-perusahaan yang melaksanakan Orientasi Pasar akan terlihat dari dari seberapa besar pemahaman mereka untuk memenuhi kebutuhan pelanggan saat ini dan masa depan serta menggunakan kemampuan mereka untuk menawarkan solusi kebutuhan yang lebih unggul daripada pesaing (Slater dan Narver, 2000).

$\begin{array}{llr}\text { Orientasi Pasar memiliki pengaruh } \\ \text { terhadap kinerja organisasi } & \text { secara } \\ \text { keseluruhan (Bearden, Kirca } & \text { dan } \\ \text { Jayachandran, 2005) } & & \end{array}$

Berdasarkan uraian yang dikemukakan diatas, maka dirumuskan hipotesis sebagai berikut: H1: Orientasi Pasar berpengaruh terhadap Kinerja Keuangan.

Pengaruh Orientasi Kewirausahaan terhadap Kinerja Keuangan Selanjutnya Silvisih, Slamet dan Iskandar (2010) juga menghimpun beberapa hasil penelitian yang menunjukkan bahwa Orientasi Kewirausahaan berpengaruh terhadap Kinerja Usaha, yaitu: Orientasi Kewirausahaan adalah faktor utama untuk meningkatkan kinerja perusahaan, maka dengan pemimpin yang berorientasi 
wirausaha dan mempunyai visi yang jelas serta berani untuk menghadapi risiko sehingga mampu menciptakan kinerja unggul (Hoorn, Brantjes and Frese, 2002).

Kinerja perusahaan yang lebih baik dapat mendorong timbulnya orientasi kewirausahaan. Ia juga mempercayai bahwa pengaruh orientasi kewirausahaan terhadap kinerja perusahaan lebih besar terlihat pada Usaha Kecil Menengah (Rauch et al 2009)

Orientasi Kewirausahaan dapat menjadi kontributor penting bagi keberhasilan perusahaan. Orientasi kewirausahaan merupakan sumber daya dan kemampuan yang menyajikan keunggulan kompetitif dan kinerja yang unggul bagi suatu perusahaan (Mahmood dan Hanafi, 2013).

Penelitian menunjukkan hasil positif mengenai pengaruh Orientasi Kewirausahaan bagi pertumbuhan perusahaan kecil (Aykol dan Gurbuz, 2009).

Penelitian yang dilakukan di Cina menemukan bahwa orientasi kewirausahaan berpengaruh positif terhadap kinerja perusahaan (Tang et al, 2007).

Penelitian yang dilakukan untuk menguji hubungan antara Orientasi Kewirausahaan dengan pertumbuhan Usaha Kecil Menengah (UKM) di Turki menunjukkan hasil bahwa Orientasi Kewirausahaan mempengaruhi pertumbuhan perusahaan (Gurbuz dan Aykol, 2009).

Penelitian tentang hubungan antara Orientasi Kewirausahaan dengan kinerja perusahaan di Cina dan menemukan bahwa orientasi kewirausahaan memiliki pengaruh yang signifikan terhadap profitabilitas perusahaan terutama untuk perusahaan bukan milik negara (Chow, 2006).

Penelitian terhadap hubungan Orientasi Kewirausahaan dengan informasi pasar terhadap kinerja Usaha Kecil Menengah di Singapura menemukan bahwa Orientasi Kewirausahaan mempunyai peran penting dalam meningkatkan kinerja perusahaan serta memiliki efek langsung dan tidak langsung pada kinerja perusahaan (Nguyen, Keh, and Ng, 2007).
Berdasarkan uraian yang dikemukakan diatas, maka dirumuskan hipotesis sebagai berikut: H2 : Orientasi Pasar berpengaruh terhadap Kinerja Keuangan

Pengaruh Orientasi Kewirausahaan terhadap Kinerja Keuangan, selanjutnya Narastika dan Yasa (2007) juga menghimpun beberapa hasil penelitian yang menunjukkan bahwa Inovasi berpengaruh terhadap Kinerja, yaitu:

Inovasi mempunyai peranan penting untuk mengurangi kendala-kendala, dalam peningkatan perhatian dan dukungan pasar. Inovasi perusahaan akan lebih berhasil merespon lingkungannya dan mengembangkan kemampuan yang dapat berdampak pada kinerja secara keseluruhan (Widarti, 2011).Inovasi memiliki pengaruh yang signifikan positif terhadap kinerja pemasaran (Pardi et al. 2014)

Inovasi produk berpengaruh positif terhadap kinerja perusahaan (Tung, 2012).

Inovasi berpengaruh positif dan signifikan terhadap kinerja pemasaran pada Industri Kecil Menengah Kerajinan Rotan Desa Teluk Wetan Kecamatan Welahan Kabupaten Jepara (Utaminingsih, 2016)

Berdasarkan uraian yang dikemukakan diatas, maka dirumuskan hipotesis sebagai berikut: H3 : Inovasi berpengaruh terhadap Kinerja Keuangan.

\section{MATERI DAN METODE}

Variabel independen dalam penelitian ini adalah Orientasi Kewirausahaan, Orientasi Pasar dan Inovasi, sedangkan variabel dependen adalah Kinerja Keuangan, dengan demikian penelitian ini termasuk penelitian asosiatif. Penelitian ini dilaksanakan di Kota Bukittinggi Sumatera Barat dengan metode pengumpulan data menggunakan kuesioner yang ditujukan kepada Usaha Ekonomi Produktif Kelompok Usaha Bersama (UEP KUBe).

Dalam penelitian ini, digunakan metode pemilihan sampel dengan non probability 
sampling yaitu suatu teknik yang tidak menggunakan prosedur pemilihan peluang, melainkan hanya berdasarkan judgment pribadi penliti (Malhorta, 2005). Jadi judgment sampling adalah bentuk convenience sampling yang berisikan elemen populasi secara sengaja dipilih atas dasar penilaian pribadi peneliti (Malhotra, 2005). Adapun jumlah responden dalam penelitian ini sebanyak 110 UEP KUBe di Kota Bukittinggi Sumatera Barat.

Pertanyaan-pertanyaan dalam kuesioner dengan menggunakan skala Linkert yang terdiri dari (1) berarti sangat tidak setuju atau tidak penting; (2) tidak setuju atau jarang; (3) ragu atau kadang-kadang; (4) setuju atau sering; (5) sangat setuju atau sering. Selanjutnya pengolahan data menggunakan teknik analisis SEM (Structural Equation Model). Di samping itu, data instrumen penelitian dilakukan beberapa uji yaitu: uji validitas data, uji reliabilitas data, nilai construc reliability.

\section{HASIL DAN PEMBAHASAN}

Tanggapan Pelaku Usaha Ekonomi Produktif Kelompok Usaha Bersama (UEP KUBe), Gambaran umum karakteristik pengelola Usaha Ekonomi Produktif Kelompok Usaha Bersama (UEP KUBe) di Kota Bukittinggi berdasarkan sampel yang dihimpun sebanyak 110 pengelola usaha, diperoleh hasil sebagai berikut:

Tabel 1.Rekapitulasi Karakteristik Pengelola Usaha Ekonomi Produktif Kelompok Usaha Bersama (UEP KUBe) di Bukit tingggi.

\begin{tabular}{|r|l|l|l|l|l|}
\hline No. & \multicolumn{1}{|c|}{ Karakteristik } & \multicolumn{2}{|c|}{$\begin{array}{c}\text { Ciri-Ciri Pengelola UEP-KUBe } \\
\text { (Dominan/Utama) }\end{array}$} & \multicolumn{2}{c|}{ Persentase } \\
\hline 1 & Jenis Kelamin & Laki-laki & & $79,09 \%$ & \\
\hline 2 & Usia & $36-45$ thn & $46-55$ thn & $39,09 \%$ & $41,82 \%$ \\
\hline 3 & Pendidikan & SMA/Sederajat & Diploma & $78,18 \%$ & $10,91 \%$ \\
\hline 4 & Status Pernikahan & Menikah & & $93,64 \%$ & \\
\hline 5 & Lama Usaha & $2-4 t a h u n$ & $5-7$ tahun & $34,55 \%$ & $20,00 \%$ \\
\hline 6 & lin Usaha & Memiliki lijn Usaha & $63,64 \%$ & \\
\hline 7 & Jumlah Tenaga Kerja & $<5$ orang & $5-10$ orang & $53,64 \%$ & $42,73 \%$ \\
\hline 8 & Jumlah Kekayaan & 30jts/d 40juta & $<$ Rp.30juta & $50,00 \%$ & $12,73 \%$ \\
\hline 9 & OmzetPenjualan/ bul & 10jts/d 50juta & $<$ Rp.10juta & $43,64 \%$ & $38,18 \%$ \\
\hline
\end{tabular}

Berdasarkan Tabel 3.1. tersebut diatas, pengelola UEP KUbe mayoritas laki-laki sebanyak 79,09\% dengan rentang usia yang dominan 46 - 55 tahun $(41,82 \%)$ sedangkan untuk usia 36 - 45 tahun hanya sebanyak $39,09 \%$ dan pendidikannya mayoritas SMA/Sederajat sebanyak 78,18\% dan diploma hanya 10,91\% dan dengan status 
yang telah menikah sangat dominan (mayoritas) yaitu 93,64\%.

Adapun lamanya telah menjalankan Usaha Ekonomi Produktif Kelompok Usaha Bersama (UEP KUBe) ini yaitu $2 \mathrm{~s} / \mathrm{d} 4$ tahun sebanyak $34,55 \%$ dan 5 s/d 7 tahun sebanyak 20,00\% sehingga dapat dikatakan cukup berpengalaman dan telah memiliki izin usaha sebanyak $63,64 \%$ dengan ratarata jumlah tenaga kerja $<5$ orang $(53,64 \%)$ dan antara 5 - 10 orang sebanyak 42,73\%.

Tabel 2. Rekapitulasi Tanggapan Pengelola Usaha Ekonomi Produktif Kelompok Usaha Bersama (UEP KUBe) terhadap Pemasaran Kewirausahaan.

\begin{tabular}{|l|l|l|l|l|}
\hline No & Kewirausahaan & $\begin{array}{l}\text { Rata- Rata } \\
\text { Penilaian } \\
\text { Pengelolaan UEP } \\
\text { KUBe }\end{array}$ & $\begin{array}{l}\text { Mayoritas Rata- } \\
\text { rata Penilaian } \\
\text { Pengelola }\end{array}$ & Keterangan \\
\hline A & Orientasu Pasar & $\mathbf{4 , 1 4}$ & $\mathbf{5 6 , 2 6 \%}$ & Sangat Setuju \\
\hline 1 & Orientasi Pelanggan & 4,56 & $68,79 \%$ & Sangat Setuju \\
\hline 2 & Orientasi Pesaing & 3,85 & $52,12 \%$ & Setuju \\
\hline 3 & Koordinasi Antar Fungsi & 4,01 & $27,88 \%$ & Sangat Setuju \\
\hline B & Orientasi Kewirausahaan & $\mathbf{4 , 4 8}$ & $\mathbf{6 2 , 7 3 \%}$ & Sangat Setuju \\
\hline 1 & Kemampuan Berinovasi & 4,65 & $69,09 \%$ & Sangat Setuju \\
\hline 2 & Pro Aktif & 4,58 & $65,76 \%$ & Sangat Setuju \\
\hline 3 & Kemampuan Mengambil Risiko & 4,22 & $53,33 \%$ & Sangat Setuju \\
\hline C & Inovasi & $\mathbf{3 , 9 2}$ & $\mathbf{4 5 , 6 1 \%}$ & Setuju \\
\hline 1 & Peningkatan Mutu Produk & 4,34 & $54,85 \%$ & Sangat Setuju \\
\hline 2 & Produk Baru & 3,49 & $36,36 \%$ & Setuju \\
\hline $\begin{array}{l}\text { Rata-rata Penilaian Pengelolaan UEP } \\
\text { KUBe }\end{array}$ & 4,18 & $54,87 \%$ & Sangat Setuju \\
\hline
\end{tabular}

Pengelola usaha sangat paham terhadap kondisi pasar atas bisnis yang dilakukannya yaitu terhadap orientasi pasar yang meliputi orientasi pesaing, lenggan dan koordinasi antara fungsi dengan nilai rata-rata 4,14 (sangat setuju). Untuk orientasi kewirausahaan yang terdiri dari kemampuan berinovasi, mengambil risiko dan proaktif dengan nilai rata-rata 4,48 (sangat setuju), adapun untuk invosi (peningkatan mutu dan produk baru dengan nilai rata-rata 3,92 (setuju). Secara umum (rata-rata) untuk semua aspek yang nilai, maka tanggapan pengelola UEP KUBe secara rata-rata dengan nilai 4,18 (sangat setuju) dan mayoritas rata-rata penilaian pengelolan sebesar $54,87 \%$.

\section{Pengujian Instrumen Penelitian}

Pengujian atas instrument yang digunakan untuk menguji kelayakan data yang akan digunakan dilakukan sebagai berikut:

\section{Uji validitas data}

Untuk melakukan uji validitas data ini, terdapat beberapa macam alat uji yang bisa digunakan. Untuk penelitian ini dilaksanakan dengan cara melakukan korelasi bivariate atas masing-masing skor indikator dengan dengan total skor indikator masing-masingnya (dengan bantuan aplikasi statistik IBM SPSS Statistics).

Berdasarkan hasil perhitungan maka diperoleh nilai $r$ hitung (atas masing-masing pertanyaan) lebih besar dari $r$ tabel, maka 
dapat disimpulkan bahwa seluruhnya datanya valid untuk digunakan dalam proses selanjutnya.

\section{Uji reliabilitas data}

Suatu kuesioner merupakan indikator dari konstruk atau variabel, maka perlu diukur reliabilitasnya atau kehandalannya sebelum Tabel 3. Hasil Uji Reliabilitas digunakan untuk kajian selanjutnya. Kehandalannya diukur dari jawaban terhadap pertanyaan yang diajukan, untuk itu perlu dilihat konsistensi jawabannya dari waktu ke waktu. Dalam penelitian ini pengujiannya dilakukan dengan apalikasi statistik (IBM SPSS Statistics) yaitu dengan uji statistik cronbach alpha (a).

\begin{tabular}{|c|c|c|c|c|}
\hline No. & $\begin{array}{c}\text { Nama } \\
\text { Konstruks }\end{array}$ & \multicolumn{3}{|c|}{ Cronbachs Alpha } \\
\hline \multirow{3}{*}{1.} & \multirow{3}{*}{$\begin{array}{l}\text { Prespektif } \\
\text { Keuangan }\end{array}$} & \multicolumn{3}{|c|}{ Reliability Statistics } \\
\hline & & $\begin{array}{l}\text { Cronbach's } \\
\text { Alpha }\end{array}$ & $\begin{array}{l}\text { Cronbach's Alpha Based on } \\
\text { Standardized Items }\end{array}$ & $\mathrm{N}$ of Items \\
\hline & & .889 & .887 & $g$ \\
\hline \multirow{3}{*}{2.} & \multirow{3}{*}{$\begin{array}{l}\text { Orientasi } \\
\text { Pasar }\end{array}$} & \multicolumn{3}{|c|}{ Reliability Statistics } \\
\hline & & $\begin{array}{c}\text { Cronbach's } \\
\text { Alpha }\end{array}$ & $\begin{array}{l}\text { Cronbach's Alpha Based } \\
\text { on Standardized Items }\end{array}$ & $\mathrm{N}$ of Items \\
\hline & & .909 & .937 & 10 \\
\hline \multirow{3}{*}{3.} & \multirow{3}{*}{$\begin{array}{l}\text { Orientasi } \\
\text { Kewirausa- } \\
\text { haan }\end{array}$} & \multicolumn{3}{|c|}{ Reliability Statistics } \\
\hline & & $\begin{array}{l}\text { Cronbach's } \\
\text { Alpha }\end{array}$ & $\begin{array}{l}\text { Cronbach's Alpha Based } \\
\text { on Standardized Items }\end{array}$ & $\mathrm{N}$ of Items \\
\hline & & .860 & .879 & 9 \\
\hline \multirow{3}{*}{4.} & \multirow{3}{*}{$\begin{array}{l}\text { Inovasi } \\
\text { Produk }\end{array}$} & \multicolumn{3}{|c|}{ Reliability Statistics } \\
\hline & & $\begin{array}{l}\text { Cronbach's } \\
\text { Alpha }\end{array}$ & $\begin{array}{c}\text { Cronbach's Alpha Based } \\
\text { on Standardized Items }\end{array}$ & $\mathrm{N}$ of Items \\
\hline & & .706 & .720 & 6 \\
\hline
\end{tabular}

Berdasarkan uji ini, ternyata untuk semua konstruk menghasilkan nilai Cronbach alpha lebih besar dari 0,60, maka dapat disimpulkan semua konstruk tersebut reliabel (handal) untuk digunakan dalam proses selanjutnya. Hal ini disebabkan nilai cronbach's alpha lebih besar dari 0,60 dapat dikatakan data tersebut reliabel (handal) (Nunnally, 1967 dalam Ghozali, 2001).

\section{Nilai Constuct Reliability}

Seluruh nilai construct reliability atas masing-masing variabel-variabel yang digunakan dalam penelitian, harus memenuhi syarat-syarat nilai yang ditentukan yaitu tingkat reliability yang dapat diterima yaitu 0,70 (Ferdinand, 2002). 
Tabel 4. Reliabilitas Konstruk

Tabel 3.3. Reliabilitas Konstruk

\begin{tabular}{|c|c|c|c|c|c|c|c|c|c|c|c|}
\hline No. & Indikator dan Variabel & $\begin{array}{l}\text { Standard } \\
\text { Loading }\end{array}$ & $\begin{array}{l}\text { Standard } \\
\text { Loading2 }\end{array}$ & $\begin{array}{c}\text { Musuremert } \\
\text { enor (1-Strd } \\
\text { Loading) }\end{array}$ & $\begin{array}{c}\text { Construct } \\
\text { Reliability }\end{array}$ & No. & Indikator dan Variabel & $\begin{array}{l}\text { Standard } \\
\text { Loading }\end{array}$ & $\begin{array}{l}\text { Standard } \\
\text { Loading2 }\end{array}$ & $\begin{array}{c}\text { Masurement } \\
\text { entror (1-std } \\
\text { Loading2) }\end{array}$ & $\begin{array}{l}\text { Construct } \\
\text { Reliability }\end{array}$ \\
\hline 1 & X1 <---Kinerja_Keuangan & 0,843 & 0,711 & 0,289 & \multirow{9}{*}{0,884} & 19 & $X 43<--$ Orientasi_Kewira usahaan & 0,727 & 0,529 & 0,471 & \multirow{9}{*}{0,914} \\
\hline 2 & X2<---Kinerja_Keuangan & 0,780 & 0,608 & 0,392 & & 20 & X44<--Orientasi_Kewirausahaan & 0,723 & 0,523 & 0,477 & \\
\hline 3 & X3 <---Kinerja_Keuangan & 0,804 & 0,646 & 0,354 & & 21 & X45 <--Orientasi_Kewira usahaan & 0,760 & 0,578 & 0,422 & \\
\hline 4 & X4<---Kinerja_Keuangan & 0,760 & 0,578 & 0,422 & & 22 & $X 46<--$ Orientasi_Kewirausahaan & 0,828 & 0,686 & 0,314 & \\
\hline 5 & X5 <---Kinerja_Keuangan & 0,799 & 0,638 & 0,362 & & 23 & X47 <--Orientasi_Kewirausahaan & 0,785 & 0,616 & 0,384 & \\
\hline 6 & $X 6<--$ Kinerja_Keuangan & 0,380 & 0,144 & 0,856 & & 24 & X48<--Orientasi_Kewirausahaan & 0,716 & 0,513 & 0,487 & \\
\hline 7 & $X 7<--$ Kinerja_Keuangan & 0,583 & 0,340 & 0,660 & & 25 & X49 <-Orientasi_Kewirausahaan & 0,584 & 0,341 & 0,659 & \\
\hline 8 & X8 <---Kinerja_Keuangan & 0,621 & 0,386 & 0,614 & & 26 & X50<--Orientasi_Kewirausahaan & 0,477 & 0,228 & 0,772 & \\
\hline \multirow[t]{2}{*}{9} & X9<---Kinerja_Keuangan & 0,444 & 0,197 & 0,803 & & 27 & X51 ---Orientasi_Kewirausahaan & 0,960 & 0,922 & 0,078 & \\
\hline & Jumlah & 6,014 & 4,249 & 4,751 & & & Jumlah & 6,560 & 4,934 & 4,066 & \\
\hline 10 & X34<---Orientasi_Pasar & 0,643 & 0,413 & 0,587 & \multirow{9}{*}{0,922} & 28 & X52<-- Inovasi & 0,589 & 0,347 & 0,653 & \multirow{6}{*}{0,781} \\
\hline 11 & X35 <---Orientasi_Pasar & 0,616 & 0,379 & 0,621 & & 29 & X53<-- Inovasi & 0,753 & 0,567 & 0,433 & \\
\hline 12 & X36<--Orientasi_Pasar & 0,618 & 0,382 & 0,618 & & 29 & X54 $<-$ - Inovasi & 0,732 & 0,536 & 0,464 & \\
\hline 13 & X37 <--_Orientasi_Pasar & 0,825 & 0,681 & 0,319 & & 30 & X55<-- Inovasi & 0,322 & 0,104 & 0,896 & \\
\hline 14 & X38<---Orientasi_Pasar & 0,822 & 0,676 & 0,324 & & 31 & X56<-- Inovasi & 0,300 & 0,090 & 0,910 & \\
\hline 15 & X39 <---Orientasi_Pasar & 0,840 & 0,706 & 0,294 & & 32 & X57 <-- Inovasi & 0,320 & 0,102 & 0,898 & \\
\hline 16 & X40<--Orientasi_Pasar & 0,830 & 0,689 & 0,311 & & & Jumlah & 3,016 & 1,746 & 4,254 & \\
\hline 17 & X41<---Orientasi_Pasar & 0,843 & 0,711 & 0,289 & & & & & & & \\
\hline \multirow[t]{2}{*}{18} & X42 <---Orientasi_Pasar & 0,707 & 0,500 & 0,500 & & & & & & & \\
\hline & Jumlah & 6,744 & 5,136 & 3,864 & & & & & & & \\
\hline
\end{tabular}

Berdasarkan hasil kalkulasi yang disajikan pada tabel 4 tersebut diatas, ternyata menunjukkan nilai construct reliability keseluruhannya lebih besar dari 0,70. Hal ini menunjukkan bahwa dimensi yang dipakai pada penelitian ini dapat mewakili konstruk yang dikembangkan yaitu kinerja keuangan, orientasi pasar, orientasi kewirausahaan dan inovasi, karena mempunyai konsistensi indikator-indikator yang digunakan.

\section{Nilai Estimate Standardized}

Tabel 5. Nilai Estimasi Parameter

\begin{tabular}{|l|c|}
\hline \multicolumn{2}{|c}{ Estimate Standardized } \\
\hline Kinerja Keuangan <----- Orientasi Kewirausahaan & 0,558 \\
\hline Kinerja Keuangan <----- Orientasi Pasar & 0,593 \\
\hline Kinerja Keuangan <----- Inovasi & $-0,589$ \\
\hline
\end{tabular}

Pada tabel 5 tersebut diatas, diperoleh Kinerja Keuangan sebesar 0,558 Orientasi Kewirausahaan, pengaruh Orientasi Kewirausahaan terhadap Kinerja Keuangan bernilai positif. Kondisi ini menunjukkan bahwa semakin baik Orientasi Kewirausahaan yang dilakukan pelaku Usaha Ekonomi Produktif Kelompok Usaha Bersama (UEP KUBe), maka semakin baik pula Orientasi Kewirausahaannya.

Kinerja Keuangan = 0,593 Orientasi Pasar, pengaruh Orientasi Pasar terhadap Kinerja Keuangan bernilai positif. Kondisi ini menunjukkan bahwa semakin baik Orientasi Pasar yang dilakukan oleh pelaku UEP KUBe, maka semakin tinggi Kinerja Keuangan yang didapatkan oleh Usaha Ekonomi Produktif Kelompok Usaha Bersama (UEP KUBe). 
Kinerja Keuangan $=-0,589$ Inovasi, perngaruh Inovasi terhadap Kinerja Keuangan bernilai negatif. Hal ini menyatakan bahwa semakin meningkatnya Inovasi, maka akan menurunkan Kinerja Keuangan, karena Inovasi tesebut membutuhkan dana (biaya) yang cukup besar bagi Usaha Ekonomi Produktif Kelompok Usaha Bersama (UEP KUBe).

\section{Nilai Standardized Direct, Indirect dan Total Effect}

Tabel 6. Nilai Standardized Direct, Indirect dan Total Effec.

\begin{tabular}{|l|c|c|c|}
\hline & Direct Effect & Indirect Effect & Total Effect \\
\hline $\begin{array}{l}\text { Kinerja Keuangan -----> } \\
\text { Orientasi Kewirausahaan }\end{array}$ & 0,558 & - & 0,558 \\
\hline $\begin{array}{l}\text { Kinerja Keuangan -----> } \\
\text { Orientasi Pasar }\end{array}$ & 0,593 & - & 0,593 \\
\hline $\begin{array}{l}\text { Kinerja Keuangan ------> } \\
\text { Inovasi }\end{array}$ & $-0,589$ & - & $-0,589$ \\
\hline
\end{tabular}

Berdasarkan tabel 3.6 yang dikemukakan tersebut diatas, bahwa Kinerja Keuangan memiliki pengaruh langsung terhadap Orientasi Kewirausahaan sebesar 0,558. Kinerja Keuangan juga memiliki pengaruh secara langsung terhadap Orientasi Pasar sebesar 0,593. Kinerja Keuangan juga memiliki pengaruh secara langsung terhadap Inovasi sebesar - 0,589.

\section{Nilai Standardized Direct, Indirect dan Total Effect}

Tabel 7. Scalar Estimates

\begin{tabular}{|l|c|c|c|c}
\hline \multicolumn{1}{|c|}{ Direct Effect } & Estimate Standardized & $C R$ & $p$-value & Keterangan \\
\hline $\begin{array}{l}\text { Kinerja Keuangan -----> } \\
\text { Orientasi Kewirausahaan }\end{array}$ & 0,558 & 2,670 & 0,008 & Signifikan \\
\hline $\begin{array}{l}\text { Kinerja Keuangan ------> } \\
\text { Orientasi Pasar }\end{array}$ & 0,593 & 4,319 & $* * * *$ & Signifikan \\
\hline $\begin{array}{l}\text { Kinerja Keuangan ------> } \\
\text { Inovasi }\end{array}$ & $-0,589$ & $-2,170$ & 0,030 & Signifikan \\
\hline
\end{tabular}

Berdasarkan tabel 7 dapat diketahui bahwa Kinerja Keuangan terhadap Orientasi Kewirausahaan memiliki p-value sebesar 0,008 . Hal ini menunjukkan bahwa pengaruh antara Kinerja Keuangan dengan Orientasi Kewirausahaan signifikan dan dapat diterima, karena nilai p-value kurang dari 0,05 .

Kinerja Keuangan terhadap Orientasi Pasar memiliki p-value sebesar 0,000. Hal ini menunjukkan bahwa pengaruh antara Kinerja Keuangan dengan Orientasi Pasar signifikan dan dapat diterima, karena nilai pvalue kurang dari 0,05.

Kinerja Keuangan terhadap Inovasi memiliki p-value sebesar 0,030. Hal ini menunjukkan bahwa pengaruh antara Kinerja Keuangan dengan Inovasi signifikan dan dapat diterima, karena nilai p-value kurang dari 0,05.

\section{Hasil Pengujian Hipotesis}

Tabel 8. Pengujian Hipotesis.

\begin{tabular}{|l|c|c|c|c|c|}
\hline \multicolumn{1}{|c|}{ Konstruks } & $\boldsymbol{b}$ & $\boldsymbol{S . E}$ & $\boldsymbol{C R}$ & $\boldsymbol{p}$-value & Kesimpulan \\
\hline $\begin{array}{l}\text { Kinerja Keuangan <----- } \\
\text { Orientasi Kewirausahaan }\end{array}$ & 1,295 &, 485 & 2,670 & 0,008 & Tidak ditolak \\
\hline $\begin{array}{l}\text { Kinerja Keuangan <------ } \\
\text { Orientasi Pasar }\end{array}$ & 0,928 &, 215 & 4,319 & $* * * *$ & Tidak ditolak \\
\hline $\begin{array}{l}\text { Kinerja Keuangan <------- } \\
\text { Inovasi }\end{array}$ & $-1,664$ &, 767 & $-2,170$ & 0,030 & Tidak ditolak \\
\hline
\end{tabular}

Memperhatikan hasil pada tabel 8 bahwa pengujian hipotesis kesatu menunjukkan Orientasi Kewirausahaan berpengaruh positif dan signifikan terhadap Kinerja Keuangan bagi Usaha Ekonomi Produktif Kelompok Usaha Bersama (UEP KUBe) di Kota Bukittinggi. Hal ini mendukung hasil penelitian di Sri Lanka yang menyatakan bahwa orientasi kewirausahaan signifikan dan positif mempunyai pengaruh terhadap kinerja UKM sektor manufaktur garmen (Kumara et al., 2014 dalam Silviasih, Slamet dan Iskandar, 2016)

Apabila orientasi kewirausahaan semakin tinggi, maka kinerja usaha UKM sektor manufaktur garmen semakin tinggi pula. Orientasi kewirausahaan adalah kunci sukses untuk memperbaiki / meningkatkan kinerja usaha, karena pengelola usaha yang berorientasi wirausaha akan memiliki visi, misi yang berani dan jelas untuk menghadapi risiko pengelolaan usaha, sehingga mampu menciptakan kinerja usaha yang lebih baik dan pada umummnya lebih efektif dalam memperbaiki kinerja (Madsen, 2005 dalam Silviasih, Slamet dan Iskandar, 2016).

Orientasi Pasar juga mempunyai pengaruh yang signifikan dan positif terhadap Kinerja Keuangan bagi Usaha Ekonomi Produktif Kelompok Usaha Bersama (UEP KUBe) di Kota Bukittinggi. Hal ini jmendukung hasil penelitian di Sri Lanka yang menyatakan bahwa orientasi kewirausahaan signifikan 
dan positif mempunyai pengaruh terhadap kinerja UKM sektor muga anufaktur garmen (Kumara et al., 2014 dalam Silviasih, Slamet dan Iskandar, 2016). UKM sektor manufaktur garmen yang berorientasi pasar, maka penginderaan pasar dan kemampuan relasinya dengan pelanggan, lebih memungkinkan untuk mencapai tujuan pemasaran dan berorientasi pada konsep pemasaran modern dan lebih kreatif serta cenderung dapat mencapai kinerja keuangan yang unggul (Erramilli et al, 2003 dalam Silviasih, Slamet dan Iskandar, 2016). Perusahaan yang berorientasi pasar pada umumnya akan memiliki kinerja yang lebih baik dalam memahami pelanggan dan pesaingnya (Greenley and Lings, 2009). Ciri utama perusahaan yang melaksanakan prinsip orientasi pasar dapat diamati dari sejauhmana pemahamannya untuk memenuhi kebutuhan pelanggan saat ini dan masa yang akan datang serta memberikan solusi untuk mengatasi kebutuhan pelanggan yang lebh baik daripada pesaing (Slate dan Narver, 2000 dalam Silviasih, Slamet dan Iskandar).

Inovasi berpengaruh signifikan tetapi negatif terhadap Kinerja Keuangan bagi Usaha Ekonomi Produktif Kelompok Usaha Bersama (UEP KUBe) di Kota Bukittinggi. Hal ini disebabkan usaha ini mempunyai keterbatasan modal untuk melakukan inovasi produk, apabila hal ini dipaksakan untuk dilaksanakan maka akan berpengaruh negatif terhadap Kinerja Keuangan. Walaupun penelitian yang dilakukan Narastika dan (Yasa, 2017) bahwa inovasi produk berpengaruh signifikan dan positif terhadap kinerja pemasaran, begitu juga (Pardi et al. 2014) menyatakan bahwa inovasi memiliki pengaruh yang positif dan signifikan terhdap kienran pemasaran. Demikian pula penelitian yang dilakukan oleh (Widarti, 2011); (Tung, 2012); Killa (2014, Utaminingsih (2016) dalam Narstika dan Yasa (2017) menyatakan bahwa inovasi berpengaruh positif terhadap kinerja.

\section{KESIMPULAN}

Pemasaran Kewirausahaan yang terdiri dari Orientasi Kewirausahaan, Orientasi Pasar dan Inovasi berpengaruh signifikan kepada Kinerja Keuangan Usaha Ekonomi Produktif Kelompok Usaha Bersama (UEP KUBe). Untuk Orientasi Kewirausahaan dan Orientasi Pasar pengaruhnya positif untuk meningkatkan Kinerja Keuangan, sedangan Inovasi pengaruhnya negatif. Hal ini disebabkan Usaha Ekonomi Produktif Kelompok Usaha Bersama (UEP KUBe) ini merupakan usaha mikro kecil, sedangkan inovasi membutuhkan biaya, yang tentunya akan berpengaruh negatif terhadap Kinerja Keuangan (terutama untuk jangka pendek).

Bagi para pelaku Usaha Ekonomi Produktif Kelompok Usaha Bersama (UEP KUBe) diharapkan untuk merubah pandangannnya akan fungsi pemasaran dalam menjalankan bisnisnya, sehingga usahanya dapat lebih meningkat dan berkembang. Ada pun bagi para peneliti selanjutnya dapat ditambahkan variabel dalam pengukuran kinerja, misalnya dengan kinerja proses bisnis internal, kinerja pertumbuhan dan pembelajaran dan lain sebagainya.

\section{DAFTAR PUSTAKA}

Aykol, S and Gurbuz, G. 2009. "Entrepreneurial Management, Entrepreneurial Orientation and Turkish Small Firm Growth." Management Research News 32 (4).

Bearden, W.O, Kirca, A.H and Jayachandran, S. 2005. "Market Orientation : A MetaAnalytic Review and Assesment of Its Antecendents and Impact of Performance." Journal of Marketing 69.

Chow, I. 2006. "The Relationship Between Entrepreneurial Orientation and Firm Performance in China." SAM Advanced Management Journal 71 (3).

Erramili, M.K, Agrawal, S. and Dev, Chekitan. S. 2003. "Market Orientation and 
Performance in Service Firms : Role of Innovation." The Journal of Service Marketing (emerald insight) 17 (1). Accessed June 28, 2019. doi:https://doi.org/10.1108/0887604 0310461282.

Ferdinand, Augusty. 2002. Structural Equition Modeling dalam Penelitian Manajemen. 2. Bandung: Badan Penerbit, Universitas Diponegoro.

Ghozali, Imam. 2011. Aplikasi Analisis Multivariate dengan Program IBM SPSS. 5. Semarang: Badan Penerbit Universitas Diponegoro.

Ginsberg, A. 2011. "Measuring Changes in Entrepreneurial Orientation Following Industry Deregulation: The Development of a Diagnostic Instrument." Proceedings of International Council of Small Business.

Greenley, G.E and Lings, I.N. 2009. "The Impact of Internal and External Market Orientations on Firm Performance." Journal of Strategic Management (Taylor \& Francis Online) 17 (1). Accessed June 29, 2019. doi:https://doi.org/10.1080/0965254 0802619251.

Greenly, G.E and Lings, I.N. 2009. "The Impact of Internal and External Market Orientations of Firm Performance." Journal of Strategic Manajement 17 (1).

Hanafi, N. and Mahmood, R. 2013. "Entrepreneurial Orientation and Business Performance of WomenOwned Small and Mediaum Enterprises in Malaysia: Competitive Advantage as a Mediator." International Journal of Business and Social Science 4 (1).

Hoor, R., Brantjes, A., Frese, M. 2002. "Psychological Succes Factors of Small Scale Business in Namibia: The Roles of Strategy Process, Entrepreneurial Orientation and the Environment." Journal of Development Entrepreneurship 7 (3).

Idar, R and Mahmood. 2011. "Entrepreneurial and Marketing Orientation Relationship to Performance : The SME Perspective."
Interdisciplinary Review of Economics and Management.

Kasali, R. 2010. Mobilisasi Intangibles Menjadi Kekuatan Perubahan. Jakarta: Gramedia.

Kelson, A.K. 2002. "A Quantitative Study of Market Orientation and Organizational Performance of Listed Componies: Evidence Form Grana." Journal of Management and Marketing Research 5 (7).

Ketchen, D.J, and Hult, G.T.M. 2001. "Does Market Orientation Matter ? : A Test of the Relationship Between Positional Advantage and Performance." Strategic Management Journal 22 (9).

Killa, Maklon Felipus. 2014. "Effect of Entrepreneurial Innovativeness Orientation, Product Innovation and Value co-Creation on Marketing Performance." Journal of Rersearch in Marketing (TechMind Research Society) 2 (3). Accessed June 28, 2019. Krohmer, H., Workman, J.P, Homburg, C. 2003. "A Strategy Implementation Prespective of Market Orientation." Journal of Business Research.

Kumara, P.A.P.S., Wijesekara, W.A.D.S, and Gunawardana, T.S.L.W. 2014. "Impact of Market Orientation and Entrepreneurial Orientation on Performance: A Study of Small and Medium Scale Grament Manufacturers in Sri Lanka." The 3rd International Conference on Management and Economics. 373 - 386.

Madsen, E.L. 2005. The Significance of Sustained Entrepreneurial Orientation on Performance of Firmsm- a Longitudinal Analysis. Working Paper, Bodo Graduate School of Business.

Mahmood, R and Shehu, A.M. 2014. "The Relationship Between Market Orientation and Business Performance of Negerian SMEs : The Role of Organizational Culture." International Journal of Business and Social Science 5 (9).

Malhorta. 2005. Riset Pemasaran. 4. Vol. 1. Jakarta: Indeks Kelompok Gramedia. 
Messaghen, K. $2003 . \quad$ "Strategic Entrepreneurship and Managerial Activities in SMEs." International Small Business Journal 21 (2).

Morris, H., and Paul, G.W. 2007. "The Relationship

Bettween Entrepreneurship and Marketing in Established Firms." Journal of Business Venturing.

Nguyen, T.T.M., Keh, H.T. and Ng, H.P. 2007. "The Effects of Entrepreneurial Orientation and Marketing Information on the Performance of SMEs." Journal of Business Venturing 22.

Pandanyi, P and Grainer, B. 2005. "The Relationship Between Market-Oriented Activities and Market-Oriented Culture: Implications for the Development of Market Orientation in Nonprofit Service Organizations." Journal of Business Research 58.

Pardi, Suharyono, Suyadi Imam dan Arifin Zainul. 2014. "The Effect of Market Orientation and Entrepreneurial Orientation toward Learning Orientation, Innovation, Competitive Advantages and Marketing Performance." European Journal of Business and Management 6 (21). Accessed July 19, 2019. https://www.iiste.org/Journals/ index.php/EJBM/article/view/14437.

Rauch, A., et al. 2009. "Entrepreneurial Orientation and Business Performance an Assesement and Past Research and Suggestions for the Future." Journal of Small Business Management 33.

RIchard, C.B, Beverly, K.B., and Michael, A.J. 2012. "Customer Orientation and Performance in Small Firms: Examining Influence of Risk Taking, Innovativeness and Opportunity Focus." Journal of Small Business Managementg 50 (3).

Silviasih, Slamet, Franky dan Iskandar, Denny. 2016. "Pengaruh Orientasi Pasar dan Orientasi Kewirausahaan terhadap Kinerja Usaha pada Pemilik UKM Sektor Manufaktur Gramen di
Tanah Abang Jakarta Pusat." Jurnal Ilmiah Manajemen Bisnis (Fakultas Ekonomi- Universitas Kristen Krida Wacana). Accessed Mart 14, 2019. https://media.neliti.com/media/publi cations/98664-ID-pengaruh-orientasipasar-dan-orientasi-k.pdf.

Slater, S.F., and Narver, J.C. 2000. "The Positive Effect of a Market Orientation on Business Profitability: a Balanced Replication." Journal of Business Research 48 (1).

Tang, J., et al. 2007. "The Impact of Enterpreneurial Orientation and Ownership Type on Firm Performance in the Emerging Region of China." Journal of Development Entrepreneurship 12 (4).

Tung, J. 2012. "A Study of Product Innovation on Firm Performance." The International Journal of Organizational Innovation 4 (3). Accessed July 20, 2019.

https://web.a.ebscohost.com/abstract ?direct=true $\&$ profile $=$ ehost $\&$ scope $=$ sit e\&authtype $=$ crawler\&jrnl $=19431813$ $\& A N=89082705 \& h=I M A X l \% 2 b 3 Y p K j 9$ HDjYTDdhvAjq8NwCvVJF9S\%2btnehF TPsz0658fK8B9qBiIj00LE4WdIU75yU cNs15fyrbmSL9SQ\%3d\%3d\&crl=c\&re sultNs=AdminWebAuth\&resultLocal.

Utamaningsih, Adijati. 2016. "Pengaruh Orientasi Pasar, Inovasi dan Kreativitas Strategi Pemsaran terhadap Kinerja Pemasaran pada UKM Kerajinan Rotan di Desa Teluk Wetan, Welahan, Jepara." Media Ekonomi dan Manajemen 13 (2). Accessed July 23, 2019. doi:http://dx.doi.org/10.24856/mem. v31i2.411.

Vorhies, D.W., Morgan, R.E., and Autry, C.W. n.d. "Product-Market Strategy and the Marketing Capabilities of the Firm : Impact on Market Effectiveness and Cash Flow." Strategic Management Journal 30 (12).

Widarti, Dyah Tri. 2011. "Pengaruh Orientasi Pasar dan Inovasi Produk terhadap Kinerja (Studi Kasus pada Sentra 
Industri Pembuatan Tahu Kecamatan Sragen Kabupaten Sragen." Skripsi (Universitas Negeri Semarang). Accessed July 19, 2019. https://lib.unnes.ac.id/232/1/7026.p df.

Wijesekara and Kumara, Gunawardana,. 2014. "Impact of Market Orientation and Entrepreneurial Orientation on Performance: a Study of Smal and Medium Scale Garment Manufactures in Si Lanka." Proceedings of the 3rd International Conference on Management and Economics.
Yasa, Ni Nyoman Kerti dan Narastika, A.A.Rai. 2017. "Peran Inovasi Produk dan Keunggulan Bersaing Memediasi Pengaruh Orientasi Pasar terhadap Kinerja Pemasaran." Jurnal Il;mu Manajemen 7 (1). Accessed June 15, 2019. http://jurnal.unmas.ac.id/ index.php/JUIMA/article/view/639.

Zahra, S., and Covin, J. 1995. "Contextual Infuences on the Corporate Entrepreneurship - Perfomance Realtionship: a Lingitudinal Analysis,." Journal of Busness Venturing. 